\title{
Sacral Chordoma
}

\section{Can Local Recurrence After Sacrectomy Be Predicted?}

\author{
S. A. Hanna MRCS, W. J. S. Aston FRCS (Orth), \\ T. W. R. Briggs MCh (Orth), FRCS, \\ S. R. Cannon MCh (Orth), FRCS, A. Saifuddin MRCP, FRCR
}

Received: 15 January 2008/ Accepted: 6 June 2008/Published online: 27 June 2008

(C) The Association of Bone and Joint Surgeons 2008

\begin{abstract}
Surgical resection margins are reportedly the most important predictor of survival and local recurrence with sacral chordomas. We examined the relevance of invasion of the surrounding posterior pelvic musculature (piriformis and gluteus maximus) at initial diagnosis to local recurrence after sacrectomy. We retrospectively reviewed 18 patients with histologically verified sacral chordoma seen at our institution between 1998 and 2005. There were 14 men and four women with a mean age of 65.1 years (range, 31-78 years). The average overall followup was 4.4 years (range, 0.5-10 years), 5.4 years for the living patients (range, 3-10 years), and 2.8 years for the deceased (range, 0.5-5.4 years). Local recurrence occurred in 12 patients (66\%) 29 months postoperatively (range, 2-84 months). Six of these patients had wide excisions at initial surgery, five had marginal excisions, and one had an intralesional excision. Ten patients had wide surgical margins, six of whom (60\%) had local
\end{abstract}

Each author certifies that he or she has no commercial associations (eg, consultancies, stock ownership, equity interest, patent/licensing arrangements, etc) that might pose a conflict of interest in connection with the submitted article.

Each author certifies that his or her institution has approved the reporting of these cases, that all investigations were conducted in conformity with ethical principles of research, and informed consent for participating in the study was obtained.

S. A. Hanna ( $\varangle)$, W. J. S. Aston, T. W. R. Briggs, S. R. Cannon Sarcoma Unit, Department of Orthopaedic Oncology, Royal National Orthopaedic Hospital, Stanmore, Middlesex

HA7 4LP, UK

e-mail: sammyhanna@hotmail.com

\section{A. Saifuddin}

Department of Radiology, London Bone \& Soft Tissue Tumour Service, Royal National Orthopaedic Hospital, Stanmore, UK recurrences. Tumor invasion of adjacent muscles at presentation was present in 14 patients, 12 of whom (85\%) had local recurrences. Sacroiliac joint involvement was seen in 10 patients, nine of whom $(90 \%)$ had local recurrences. The findings suggest obtaining wide surgical margins posteriorly, by excising parts of the piriformis, gluteus maximus, and sacroiliac joints, may result in better local disease control in patients with sacral chordoma.

Level of Evidence: Level IV, prognostic study. See the Guidelines for Authors for a complete description of levels of evidence.

\section{Introduction}

Chordomas are rare malignant tumors arising from embryonic notochordal remnants and accounting for $17.5 \%$ of primary malignant bone tumors of the axial skeleton, with a reported incidence of 0.5 to 0.8 per $1,000,000$ population [13, 22]. Luschka (1856) and Virchow (1857) first described the condition under the name of 'ecchondrosis physaliphora', believing these were cartilaginous. Muller (1858) was the first to recognize its origin from notochordal cells, and Ribbert (1894) first introduced the term 'chordoma' $[19,30]$. Lesions arise from the sacrococcygeal region $(50 \%)$, base of the skull $(35 \%)$, and vertebral bodies $(15 \%)$ [9, 11]. Sacral chordomas grow slowly and metastasize late in $20 \%$ to $40 \%$ of patients, to the lungs, liver, bone, and soft tissues. Ten-year survival ranges from $30 \%$ to $65 \%[3,4,15,16,18,24,31]$. Complete surgical excision is a prerequisite to prolonged survival. Although numerous authors report surgical resection margins the most important predictor of survival and local recurrence, cure is rare and recurrence is not uncommon $[2,10,11,25]$. 
We examined the relevance of tumor invasion of the surrounding posterior pelvic musculature (piriformis and gluteus maximus) and adjacent sacroiliac joints to the development of local recurrence and its relationship with surgical margins.

\section{Materials and Methods}

We identified and retrospectively reviewed the records of 22 patients from our histopathology database with histologically verified sacral chordomas and preoperative MRI; all patients were seen and treated between 1998 and 2005. Four patients, whom we saw for local recurrences after initial treatment elsewhere, were excluded. We reviewed the records of the remaining 18 patients to determine the relationship between invasion of adjacent muscles and joints to the development of local recurrence of tumor. We obtained clinical data from case notes, hospital databases, imaging studies, and outpatient clinic notes. There were 14 men and four women with a mean age of 65.1 years (range, 31-78 years). The average overall followup was for 4.4 years (range, $0.5-10$ years), 5.4 years for the living patients (range, 3-10 years), and 2.8 years for the deceased (range, 0.5-5.4 years). Preoperative radiographs were available for all patients. Mean radiographic dimensions of the primary tumor were $11.5 \times 8.5 \times 11 \mathrm{~cm}$ (craniocaudal $\mathrm{x}$ anteroposterior $\mathrm{x}$ lateral). Preoperative MR images were available for all patients. All 18 patients also had MRI at various stages during their postoperative followup. Magnetic resonance imaging analysis was performed by an experienced consultant musculoskeletal radiologist (AS) who evaluated the images for tumor signal intensity characteristics, location in the sacrum, and involvement of the sacroiliac joints (Fig. 1) and the gluteus maximus and piriformis muscles. The relationship between the tumor and adjacent muscles was classified as no involvement (Fig. 2A), contact (Fig. 2B), or invasion (Fig. 2C-D).

The proximal extent of the tumor, involvement of the rectum, and need to perform a colostomy determined the type of surgical approach used. Preoperative imaging was evaluated carefully by a multidisciplinary team to assess the degree of tumor extension and nerve root involvement, and to discuss surgical planning. In our series, all but one patient with involvement of the S2 vertebra and above had a combined sequential anterior/posterior approach. This patient had a tumor arising from S2, but refused a combined approach and colostomy. Patients who were certain to lose bowel control because of S2 nerve roots involvement also had a combined approach with colostomy formation. Lumbosacral stabilization was performed when greater than $50 \%$ of either sacroiliac joint was resected, as this destabilizes the pelvis [16]. The anterior procedure is performed by a general
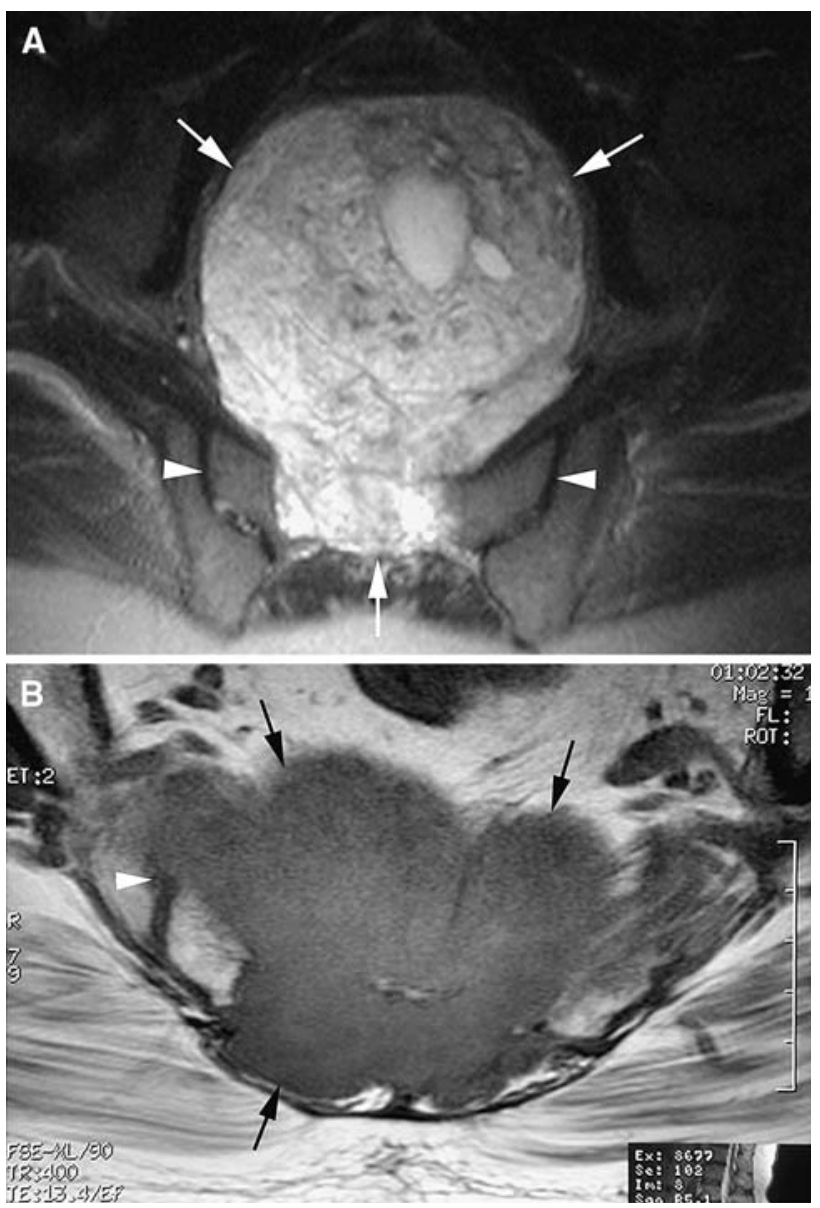

Fig. 1A-B (A) An axial fat-suppressed T2-weighted fast spin echo MR image shows a sacral chordoma with a large anterior soft tissue extension (arrows) but no involvement of the sacroiliac joints (arrowheads). (B) An axial T1-weighted spin echo MR image shows a sacral chordoma (arrows) with invasion of the right sacroiliac joint (arrowhead).

surgeon through a midline laparotomy incision. The sigmoid colon is divided just above the peritoneal reflexion in preparation for the left iliac fossa colostomy. The sacrum then is devascularized by dividing the internal iliac arteries or tying off their branches sequentially. The internal iliac veins or their branches are divided, including branches going laterally, inferiorly, and posteriorly. A plane is developed anterior to the rectum and posterior to the bladder and prostate. A pack is placed in this position to aid future final dissection. The colostomy then is fashioned, but the bowel is not opened at this stage. The omentum is fully mobilized and placed in the pelvis. A vertical rectus abdominis pull-through pedicle flap is fashioned, with the muscle dissected down to the origin of the inferior epigastric arteries. The flap is positioned loose in the pelvis. The abdominal wound then is closed and the colostomy is fashioned with a bag applied.

The patient then is laid prone. An elliptical incision curved around to include the anus, which is sutured after 
Fig. 2A-D (A) An axial T1weighted spin echo MR image shows a distal sacral chordoma (arrows) with no involvement of either piriformis (arrowheads) or gluteus maximus (double arrowheads) muscles. (B) An axial T2weighted fast spin echo MR image shows a sacral chordoma (arrows) in contact with but not invading the gluteus maximus muscles (arrowheads). (C) A coronal T1-weighted spin echo MR image shows a large sacral chordoma (arrows) invading the right piriformis muscle (arrowheads). (D) An axial T2-weighted fast spin echo MR image shows a sacral chordoma (arrows) invading both gluteus maximus muscles (arrowheads).
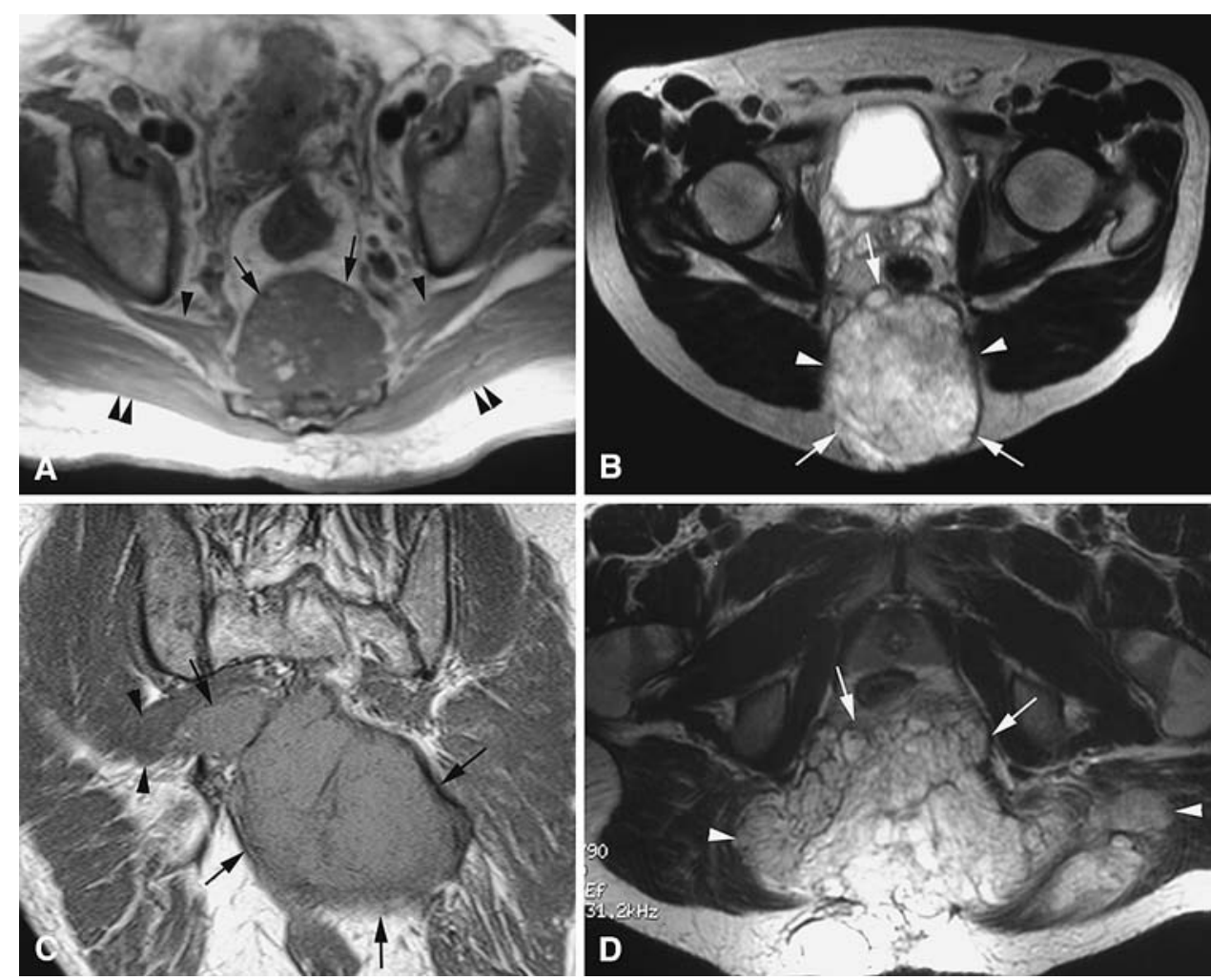

packing the anal canal with swabs, is made. Dissection then is started through the subcutaneous tissue, the fascia, and the posterior pelvic musculature maintaining a $2-\mathrm{cm}$ margin from the tumor posteriorly and laterally. The sciatic nerve is identified and preserved when possible. Only nerve roots that are definitely not involved are preserved, but those traversing the tumor are excised. The image intensifier is used to ascertain the correct level of dissection with reference to preoperative imaging. Osteotomies are made through the sacrum $2 \mathrm{~cm}$ proximal and lateral to the tumor margins. In case of sacroiliac joint involvement, parts of the ilium adjacent to the joint are resected obliquely. Blunt anterior dissection is performed on the anterior aspect of the sacrum. The tumor then is excised intact and sent for histopathologic examination. Hemostasis is obtained and the bleeding is stopped. Bone wax is used for the bony elements. Spinopelvic reconstruction with rods and pedicle screws is performed when required [16]. The omentum then is pulled through and laid across the defect posteriorly. Finally, the composite rectus abdominis myocutaneous flap is brought down, orientated, and secured in position. Eight patients had the procedure through a combined anterior/posterior approach, and 10 through a single posterior approach (Table 1).

All tissue specimens were reviewed by experienced consultant histopathologists with special interest in musculoskeletal oncology to reach a definitive diagnosis and assess the excision margins achieved. The margins were classified in accordance with the Enneking staging system [12] into wide, marginal, and intralesional.

Patients were followed at regular intervals of 3 to 4 months during the first 2 years postoperatively, every 6 months between 2 and 5 years, and on an annual basis thereafter. Plain radiographs of the operated site and the chest were obtained twice annually to identify any local recurrence and/or metastases. Computed tomography scans were obtained in case of suspected metastases, particularly pulmonary. Magnetic resonance images were obtained postoperatively at least once annually during the first 3 years and whenever there was suspicion of local recurrence. Followup MR images were evaluated for the presence of local recurrence (Fig. 3) or metastatic lesions.

\section{Results}

Twelve of 18 patients had local recurrence at a median of 24 months postoperatively (range, 2-84 months). Six of these 12 patients had wide excisions at initial surgery, five had marginal excisions, and one had an intralesional excision. Ten of 18 patients had wide surgical margins, six of whom had local recurrences at 33.8 months (range, 2-84 months). Eight patients had inadequate margins (seven marginal, one intralesional), six of whom also had local recurrences at 18.1 months (range, 6-45 months). Tumor infiltration of the surrounding musculature (piriformis and/or gluteus 


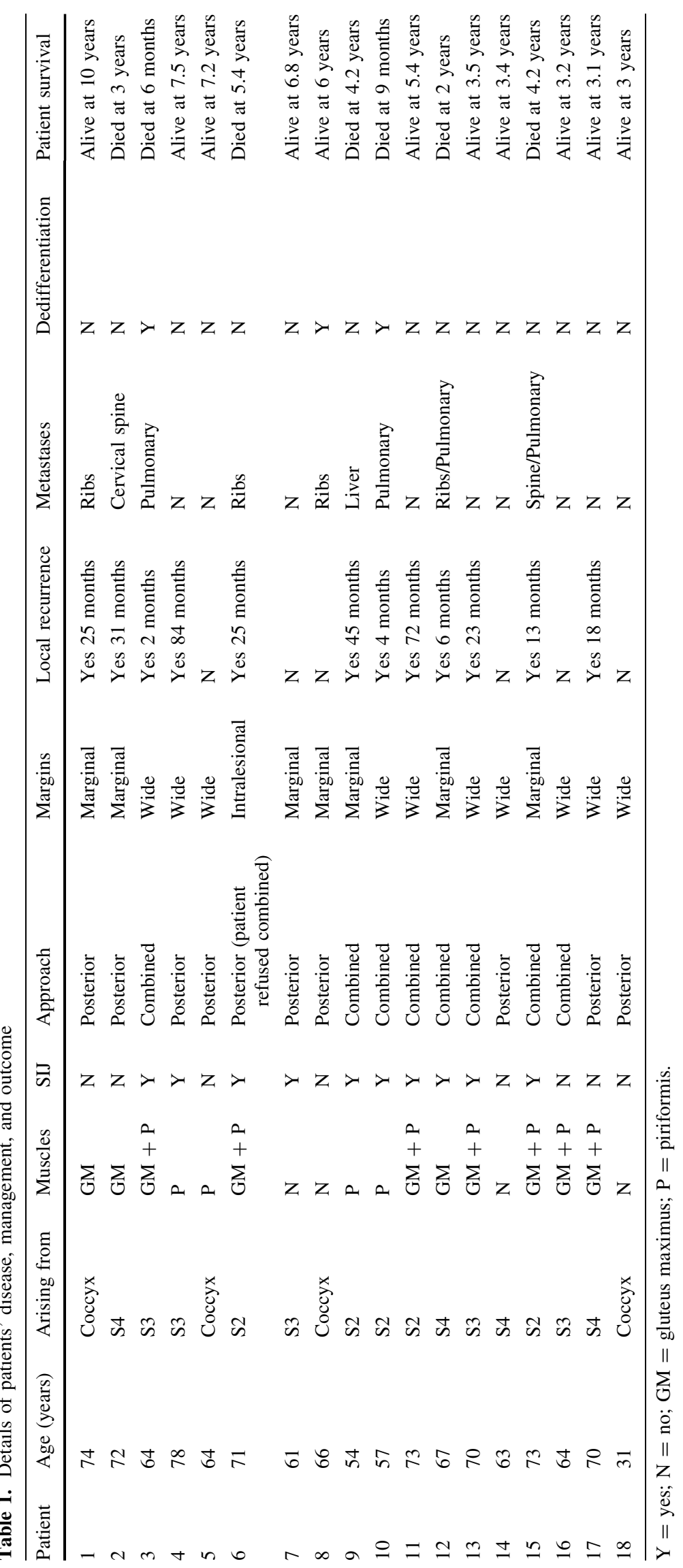




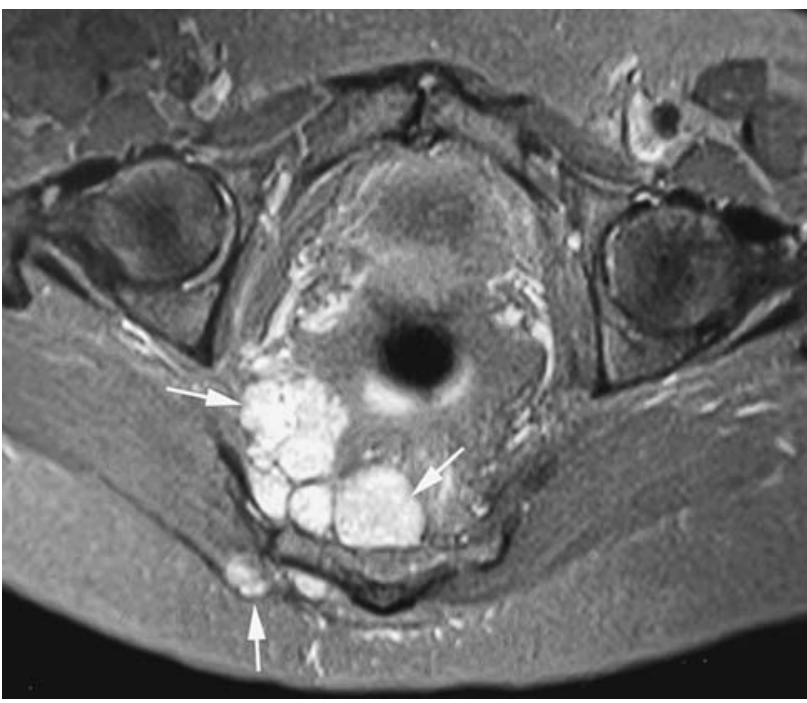

Fig. 3 An axial fat-suppressed proton density weighted MR image shows multifocal soft tissue local recurrence (arrows).

maximus) was present in 14 of 18 patients at initial diagnosis, with all 12 local recurrences occurring in this group. Sacroiliac joint involvement was present in 10 patients, eight unilaterally and two bilaterally. Nine patients in this group had local recurrences in comparison to only three of the remaining eight patients with intact sacroiliac joints. Overall, 10 patients had wide surgical margins. Of these, eight had muscle infiltration at initial diagnosis, whereas two had no muscle infiltration and did not have recurrence. Similarly, all five patients with sacroiliac joint involvement had recurrences, whereas one of five with an intact sacroiliac joints had recurrence. All 12 local recurrences were in the soft tissues/musculature posterior to the sacrum.
Seven of 18 patients died of their disease at a median of 3 years; five of these patients had inadequate surgical margins and local recurrence and metastases before death (Table 1). Tumor infiltration of the musculature and/or sacroiliac joints at initial diagnosis was present in all seven cases. Two of the deceased patients had multiple foci of high-grade spindle cell dedifferentiation in the tumor, identified after primary excision. This resulted in an aggressive clinical course, culminating in metastases and rapid demise. They died of pulmonary metastases at 6 months and 9 months, respectively.

\section{Discussion}

Complete surgical excision in sacral chordoma is essential to achieving local disease control, because of the tumor's resistance to radiotherapy and chemotherapy. However, recurrence is common even after wide en bloc resection. We examined the relevance of tumor invasion of the surrounding posterior pelvic musculature/sacroiliac joints at initial diagnosis, to the development of local recurrence, and its relationship with excision margins.

The number of patients included in this study is limited because of the rarity of sacral chordomas. In addition, some patients whom we saw for local recurrence after having their primary surgery elsewhere were excluded. Likely because these surgeries were not performed by trained orthopaedic oncologists, intralesional-type excisions were more prevalent. Limited patient numbers also occurred in similar published studies (Table 2). We included only patients with a minimum of 3 years followup. The exceptions were the two patients with dedifferentiated tumors

Table 2. Comparison of published outcomes for sacral chordomas

\begin{tabular}{|c|c|c|c|c|c|c|}
\hline Authors & Patients & Followup & LR & $\begin{array}{l}\text { LR with } \\
\text { wide margins }\end{array}$ & $\begin{array}{l}\text { LR with inadequate } \\
\text { margins }\end{array}$ & $\begin{array}{l}\text { Death rate } \\
\text { (disease related) }\end{array}$ \\
\hline \multirow[t]{2}{*}{ Bergh et al. [4] } & \multirow[t]{2}{*}{30} & \multirow[t]{2}{*}{8.1 years $(0.2-23)$} & 12 & $6 / 16$ & $6 / 14$ & 10 \\
\hline & & & $30 \%$ & $37 \%$ & $43 \%$ & $33 \%$ \\
\hline \multirow[t]{2}{*}{ Yonemoto et al. [31] } & \multirow[t]{2}{*}{13} & \multirow[t]{2}{*}{6.3 years $(0.5-13.7)$} & 6 & $0 / 3$ & $6 / 10$ & 7 \\
\hline & & & $46 \%$ & $0 \%$ & $60 \%$ & $54 \%$ \\
\hline \multirow[t]{2}{*}{ Baratti et al. [3] } & \multirow[t]{2}{*}{28} & \multirow[t]{2}{*}{5.9 years $(1.2-16.6)$} & 17 & $6 / 11$ & $11 / 17$ & 10 \\
\hline & & & $61 \%$ & $54 \%$ & $65 \%$ & $36 \%$ \\
\hline \multirow[t]{2}{*}{ York et al. [32] } & \multirow[t]{2}{*}{27} & \multirow[t]{2}{*}{3.6 years $(0.3-34)$} & 18 & $8 / 15$ & $10 / 12$ & 15 \\
\hline & & & $66 \%$ & $53 \%$ & $83 \%$ & $55 \%$ \\
\hline \multirow[t]{2}{*}{ Hulen et al. [18] } & \multirow[t]{2}{*}{16} & \multirow[t]{2}{*}{5.5 years $(1.2-14.5)$} & 12 & $9 / 16$ & $7 / 16$ & 6 \\
\hline & & & $75 \%$ & $56 \%$ & $44 \%$ & $37 \%$ \\
\hline \multirow[t]{2}{*}{ Fuchs et al. [15] } & \multirow[t]{2}{*}{52} & \multirow[t]{2}{*}{7.8 years $(2.1-23)$} & 23 & $1 / 21$ & $22 / 31$ & 19 \\
\hline & & & $44 \%$ & $5 \%$ & $71 \%$ & $36 \%$ \\
\hline \multirow[t]{2}{*}{ Current study } & \multirow[t]{2}{*}{18} & \multirow[t]{2}{*}{4.4 years $(0.5-10)$} & 12 & $6 / 10$ & $6 / 8$ & 7 \\
\hline & & & $66 \%$ & $60 \%$ & $75 \%$ & $39 \%$ \\
\hline
\end{tabular}

$\mathrm{LR}=$ local recurrence. 
who died of their disease during the first year postoperatively (6 and 9 months, respectively). Because of the limited number of patients, statistical analysis was not warranted as it would not generate meaningful results, or add any value to the data.

This review suggests infiltration of the musculature adjacent to the sacrum and/or involvement of the sacroiliac joints increases the tendency of local recurrence, even after apparently successful en bloc resection of the tumor. This is in agreement with a small study by Ishii et al. [20], who described four cases of local recurrence after S2-3 sacrectomy for chordoma despite having achieved clear resection margins. They recommended parts of the sacroiliac joints and the glutei and piriformis muscles adjacent to the sacrum be resected to reduce local recurrence rates. All the local recurrences in our patients occurred in the soft tissues posterior to the sacrum, whereas no recurrences were observed in the anterior region. This may be explained by the presence of the presacral fascia anterior to the sacrum, which seems to prevent tumor cells from going beyond it [31]. Yonemoto et al. concluded a less radical anterior margin is acceptable, whereas a wide posterior margin is crucial for local disease control [31]. We found the presence of muscle and/or sacroiliac joint involvement increased the tendency of recurrence, even after wide excision of the tumor. This may be explained by intraoperative contamination/seeding of cells from this myxoid-type tumor into healthy tissue that would not be detected during histopathologic assessment of tumor margins. Another explanation may be the presence of microscopic satellite lesions, which would not be detected by MRI. However, there is universal acceptance that achieving wide resection margins free of tumor is the most important predictor of local recurrence and survival in chordoma $[4,5,13,18,20,27$, 28]. Kaiser et al. [21] reported a $28 \%$ recurrence rate in patients with en bloc resection, but a $64 \%$ rate in patients in whom the tumor capsule was breached intraoperatively. York et al. [32] reported a disease-free interval of 2.27 years in patients with radical resection and only 8 months in patients with subtotal excision. This also was observed in our patients, as five of the seven patients who died of their disease had inadequate margins, and local recurrence and metastases developed before death (Table 1). All of our patients with wide margins but involvement of the sacroiliac joint at initial presentation had recurrences. Abdelwahab et al. [1] suggested the joint space acts as a barrier to tumor spread, and transarticular invasion of a joint by a tumor is directly related to joint mobility. This means involvement of the sacroiliac joints in sacral chordoma may indicate the tumor is at an advanced stage, therefore, the high local recurrence rate associated with this.
The mortality rate in our series was $39 \%$. This is similar to rates in other published studies (Table 2). Two of the deceased patients had primary dedifferentiated chordoma and died at 6 month and 9 months, respectively. Both had extensive local recurrence and metastases before death. The other five deceased patients had conventional chordomas. All had local recurrences, with four having metastases (Table 1).

The effect of conventional photon radiotherapy on survival is a controversial issue. Although some authors have reported an increase in tumor-free intervals after using radiotherapy for local control [26, 32], others have reported radiotherapy has little influence on overall survival $[8,9$, 28]. Two studies advocated the use of hadrons (ie, highdose protons or charged particles, such as carbon ions or helium) to improve the radiobiologic effect, mainly in cases of base of skull disease [17, 23]. The physical and ballistic properties of hadrons allow delivery of higher doses to the target volume, while sparing organs at risk [7].

Imatinib mesylate (Gleevec, Novartis Pharma AG, Basel, Switzerland), which is a tyrosine kinase inhibitor targeting platelet-derived growth factor receptor- $\beta$ (PDGFRB), is effective in treating chordoma [6]. Casali et al. recommended additional evaluation of its role as an adjunct to surgery and/or radiotherapy for management of chordoma [6].

Tumor involvement of the piriformis, gluteus maximus, and sacroiliac joints, as seen on preoperative MR images in patients with sacral chordomas, is an important predictor of the tendency of local recurrence, even after wide en bloc resection. Careful evaluation of preoperative MR images should be performed in a multidisciplinary setting to ascertain the extent of the disease and plan surgery. We recommend obtaining wide intraoperative surgical margins, especially posteriorly, by resecting parts of the posterior pelvic musculature and sacroiliac joints. Furthermore, stringent clinical and radiographic followups are paramount to remain vigilant for development of local recurrence.

\section{References}

1. Abdelwahab IF, Miller TT, Hermann G, Klein MJ, Kenan S, Lewis MM. Transarticular invasion of joints by bone tumors: hypothesis. Skeletal Radiol. 1991;20:279-283.

2. Ariel IM, Verdu C. Chordoma: an analysis of twenty cases treated over a twenty-year span. J Surg Oncol. 1975;7:27-44.

3. Baratti D, Gronchi A, Pennacchioli E, Lozza L, Colecchia M, Fiore M, Santinami M. Chordoma: natural history and results in 28 patients treated at a single institution. Ann Surg Oncol. 2003;10:291-296.

4. Bergh P, Kindblom LG, Gunterberg B, Remotti F, Ryd W, MeisKindblom J. Prognostic factors in chordoma of the sacrum and mobile spine: a study of 39 patients. Cancer. 2000;88:2122-2134. 
5. Boriani S, Bandiera S, Biagini R, Bacchini $\mathrm{P}$, Boriani L, Cappuccio M, Chevalley F, Gasbarrini A, Picci P, Weinstein JN. Chordoma of the mobile spine: fifty years of experience. Spine. 2006;31:493-503.

6. Casali PG, Messina A, Stacchiotti S, Tamborini E, Crippa F, Gronchi A, Orlandi R, Ripamonti C, Spreafico C, Bertieri R, Bertulli R, Colecchia M, Fumagalli E, Greco A, Grosso F, Olmi $\mathrm{P}$, Pierotti MA, Pilotti S. Imatinib mesylate in chordoma. Cancer. 2004;101:2086-2097.

7. Casali PG, Stacchiotti S, Sangalli C, Olmi P, Gronchi A. Chordoma. Curr Opin Oncol. 2007;19:367-370.

8. Catton C, O'Sullivan B, Bell R, Laperriere N, Cummings B, Fornasier V, Wunder J. Chordoma: long-term follow-up after radical photon irradiation. Radiother Oncol. 1996;41:67-72.

9. Cheng EY, Ozerdemoglu RA, Transfeldt EE, Thompson RC Jr. Lumbosacral chordoma: prognostic factors and treatment. Spine. 1999; 24:1639-1645.

10. Dahlin D, MacCarty C. Chordoma: a study of fifty-nine cases. Cancer. 1952;5:1170-1178.

11. Dahlin DC, Unni KK. Bone Tumors. 4th Ed. Springfield, IL: Thomas; 1986:379-391.

12. Enneking WF, Spanier SS, Goodman MA. A system for the surgical staging of musculoskeletal sarcoma. Clin Orthop Relat Res. 1980;153:106-120.

13. Eriksson B, Gunterberg B, Kindblom LG. Chordoma: a clinicopathologic and prognostic study of a Swedish national series. Acta Orthop Scand. 1981;52:49-58.

14. Forsyth PA, Cascino TL, Shaw EG, Scheithauer BW, O'Fallon JR, Dozier JC, Piepgras DG. Intracranial chordomas: a clinicopathological and prognostic study of 51 cases. J Neurosurg. 1993;78:741-747.

15. Fuchs B, Dickey ID, Yaszemski MJ, Inwards CY, Sim FH. Operative management of sacral chordoma. J Bone Joint Surg Am. 2005;87:2211-2216.

16. Gunterberg B, Romanus B, Sterner B. Pelvic strength after major amputation of the sacrum: an experimental study. Acta Orthop Scand. 1976;47:635-642.

17. Hug EB, Loredo LN, Slater JD, DeVries A, Grove RI, Schaefer RA, Rosenberg AE, Slater JM. Proton radiation therapy for chordomas and chondrosarcomas of the skull base. J Neurosurg. 1999;91:432-439.
18. Hulen CA, Temple HT, Fox WP, Sama AA, Green BA, Eismont FJ. Oncologic and functional outcome following sacrectomy for sacral chordoma. J Bone Joint Surg Am. 2006;88:1532-1539.

19. Husain F. Chordoma of the thoracic spine: report of a case. J Bone Joint Surg Br. 1960;42:560-564.

20. Ishii K, Chiba K, Watanabe M, Yabe H, Fujimura Y, Toyama Y. Local recurrence after S2-3 sacrectomy in sacral chordoma: report of four cases. J Neurosurg. 2002;97(1 suppl):98-101.

21. Kaiser T, Pritchard D, Unni KK. Clinicopathologic study of sacrococcygeal chordoma. Cancer. 1984;53:2574-2578.

22. McMaster ML, Goldstein AM, Bromley CM, Ishibe N, Parry DM. Chordoma: incidence and survival patterns in the United States, 1973-1995. Cancer Causes Control. 2001;12:1-11.

23. Munzenrider JE, Liebsch NJ. Proton therapy for tumors of the skull base. Strahlenther Onkol. 1999;175(suppl 2):57-63.

24. Osaka S, Kodoh O, Sugita H, Osaka E, Yoshida Y, Ryu J. Clinical significance of a wide excision policy for sacrococcygeal chordoma. J Cancer Res Clin Oncol. 2006;132:213-218.

25. Rich TA, Schiller A, Suit HD, Mankin HJ. Clinical and pathological review of 48 cases of chordoma. Cancer. 1985;56:182187.

26. Saxton JP. Chordoma. Int J Radiat Oncol Biol Phys. 1981;7:913915.

27. Soo MY. Chordoma: review of clinicoradiological features and factors affecting survival. Australas Radiol. 2001;45:427-434.

28. Sundaresan N, Huvos AG, Krol G, Lane JM, Brennan M. Surgical treatment of spinal chordomas. Arch Surg. 1987;122:14791482.

29. Volpe R, Mazabraud A. A clinicopathologic review of 25 cases of chordoma (a pleomorphic and metastasizing neoplasm). Am $J$ Surg Pathol. 1983;7:161-170.

30. Watkins L, Khudados ES, Kaleoglu M, Revesz T, Sacares P, Crockard HA. Skull base chordomas: a review of 38 patients, 1958-1988. Br J Neurosurg. 1993;7:241-248.

31. Yonemoto T, Tatezaki S, Takenouchi T, Ishii T, Satoh T, Moriya $\mathrm{H}$. The surgical management of sacrococcygeal chordoma. Cancer. 1999;85:878-883.

32. York JE, Kaczaraj A, Abi-Said D, Fuller GN, Skibber JM, Janjan NA, Gokaslan ZL. Sacral chordoma: 40-year experience at a major cancer center. Neurosurgery. 1999;44:74-79; discussion 79-80. 